\title{
Cortical representation sites of mimic movements after facial nerve reconstruction: a functional magnetic resonance imaging study
}

Citation for published version (APA):

Bitter, T., Sorger, B., Hesselmann, V., Krug, B., Lackner, K., \& Guntinas-Lichius, O. (2011). Cortical representation sites of mimic movements after facial nerve reconstruction: a functional magnetic resonance imaging study. Laryngoscope, 121(4), 699-706. https://doi.org/10.1002/lary.21399

Document status and date:

Published: 01/04/2011

DOI:

10.1002/lary.21399

Document Version:

Publisher's PDF, also known as Version of record

Document license:

Taverne

Please check the document version of this publication:

- A submitted manuscript is the version of the article upon submission and before peer-review. There can be important differences between the submitted version and the official published version of record.

People interested in the research are advised to contact the author for the final version of the publication, or visit the DOI to the publisher's website.

- The final author version and the galley proof are versions of the publication after peer review.

- The final published version features the final layout of the paper including the volume, issue and page numbers.

Link to publication

\footnotetext{
General rights rights.

- You may freely distribute the URL identifying the publication in the public portal. please follow below link for the End User Agreement:

www.umlib.nl/taverne-license

Take down policy

If you believe that this document breaches copyright please contact us at:

repository@maastrichtuniversity.nl

providing details and we will investigate your claim.
}

Copyright and moral rights for the publications made accessible in the public portal are retained by the authors and/or other copyright owners and it is a condition of accessing publications that users recognise and abide by the legal requirements associated with these

- Users may download and print one copy of any publication from the public portal for the purpose of private study or research.

- You may not further distribute the material or use it for any profit-making activity or commercial gain

If the publication is distributed under the terms of Article 25fa of the Dutch Copyright Act, indicated by the "Taverne" license above, 
Read all three of our prestigious publications, each offering high-quality content to keep you informed with the latest developments in the field.
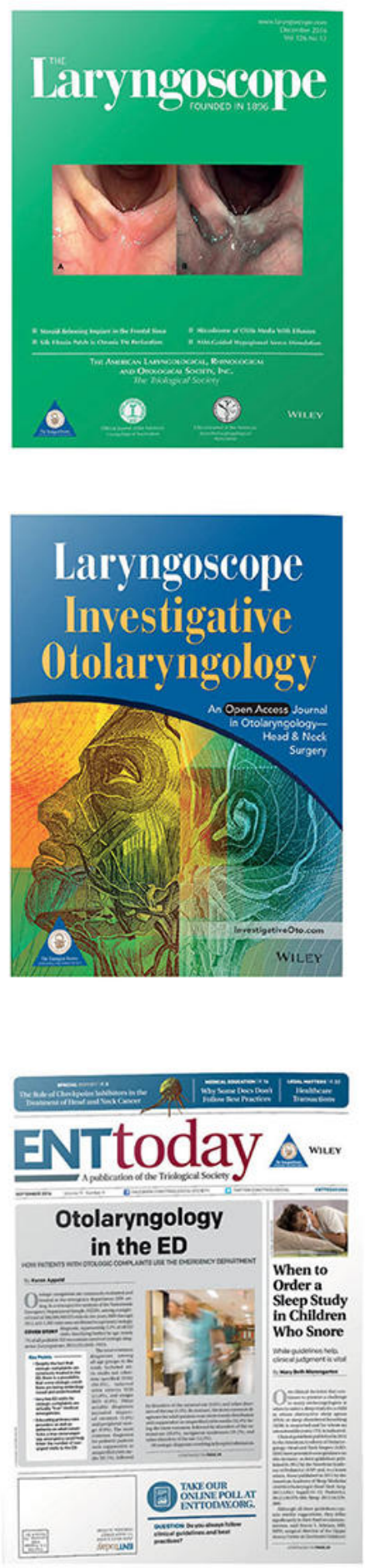

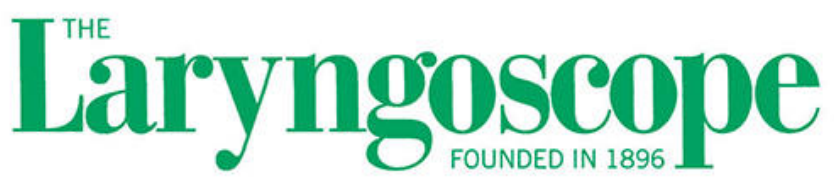

Editor-in-Chief: Samuel H. Selesnick, MD, FACS

The leading source for information

in head and neck disorders.

Laryngoscope.com

Laryngoscope

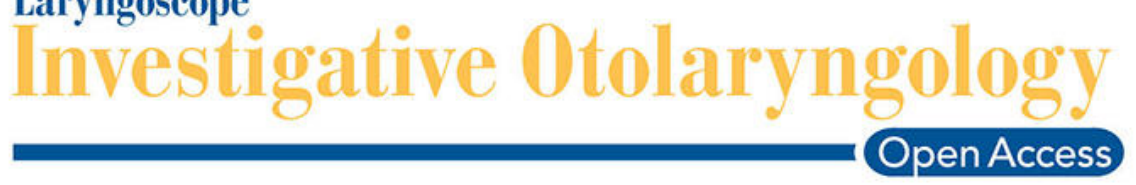

Editor-in-Chief: D. Bradley Welling, MD, PhD, FACS

Rapid dissemination of the science and practice of otolaryngology-head and neck surgery.

InvestigativeOto.com

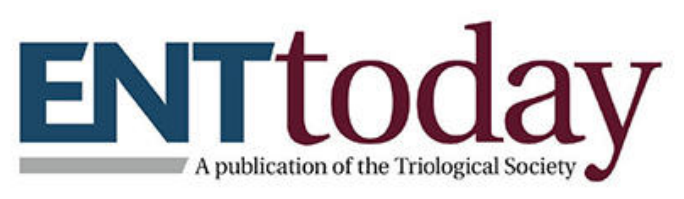

Editor-in-Chief: Alexander Chiu, MD

Must-have timely information that Otolaryngologisthead and neck surgeons can use in daily practice.

\section{Enttoday.org}




\title{
Cortical Representation Sites of Mimic Movements After Facial Nerve Reconstruction: A Functional Magnetic Resonance Imaging Study
}

\author{
Thomas Bitter, MD; Bettina Sorger, PhD; Volker Hesselmann, MD; Barbara Krug, MD; \\ Klaus Lackner, MD; Orlando Guntinas-Lichius, MD
}

\begin{abstract}
Objectives/Hypothesis: To describe cortical reorganization after classic hypoglossal-facial nerve anastomosis (HFA) (four patients), hypoglossal-facial nerve jump anastomosis (HFJA) (three patients), and facial nerve interpositional graft (FNIG) (three patients).

Study Design: Prospective case series.

Methods: Functional magnetic resonance imaging (fMRI) was performed during lip and tongue movement using a block or an event-related design.

Results: Despite the presence of some intersubject variability, the following general brain activation patterns were revealed: As expected, lip movements after FNIG led to selective brain activation in the original facial motor cortex, and lip movements after HFA were associated with activation in the hypoglossal motor cortex. Following HFJA, lip movements resulted in overlapping activation encompassing both the original facial and the hypoglossal motor cortex, but tongue movements led solely to strong activation within the original hypoglossal motor cortex. In contrast, tongue movements after HFA were associated with strong activation in the original hypoglossal motor cortex and weaker activation in the facial motor
\end{abstract} cortex.

Conclusions: Direct facial nerve repair (FNIG) leads to restoration of the original cortical activation. A cross nerve suture (HFA or HFJA) changes cortical activation and leads to different patterns of cortical activation during lip and tongue movements.

Key Words: Facial nerve, hypoglossal nerve, paralysis, nerve suture, regeneration, cortical plasticity, lip movement, tongue movement, functional magnetic resonance imaging, cortical representation.

Level of Evidence: 4.

Laryngoscope, 121:699-706, 2011

\section{INTRODUCTION}

Patients with acute peripheral facial palsy due to iatrogenic intraoperative lesion or to Bell's palsy show a widespread reorganization of the cortex. By using positron emission tomography (PET) and transcranial magnetic stimulation (TMS), it has been demonstrated in a series of nine patients that facial motor deefferentation leads to an enlargement and extension of the cortical hand field into the neighbored face area, contralaterally to the facial palsy. ${ }^{1}$ Another TMS study investigating five patients with facial palsy provided evidence that the neighbored tongue motor area also

From the Department of Otorhinolaryngology, Friedrich-SchillerUniversity Jena, Germany (т.B., o.G.-L.); Coma Science Group, Cyclotron Research Centre, University of Liège, Liège, Belgium (в.s.); Department of Cognitive Neuroscience, Faculty of Psychology and Neuroscience, Maastricht University, Maastricht, The Netherlands (B.s.); Department of Clinical Radiology, University Hospital Münster, Münster, Germany (v.H.); and Department of Radiology, University of Cologne Medical School, Germany (B.K, K.L.).

Editor's Note: This Manuscript was accepted for publication October 5, 2010.

The authors have no funding, financial relationships, or conflicts of interest to disclose.

Send correspondence to Orlando Guntinas-Lichius, MD, Department of Otorhinolaryngology, Friedrich-Schiller-University Jena, Lessingstrasse 2, D -07740 Jena, Germany.

E-mail: orlando.guntinas@med.uni-jena.de

DOI: 10.1002/lary.21399 invades the facial motor region bilaterally-although more pronounced on the contralateral side to the lesion. ${ }^{2}$

Various animal studies suggest that the reorganization of the motor cortex following facial nerve lesioning takes place within a few hours after onset of the lesion. ${ }^{3,4}$ However, little is known about the degree of reversibility of such a cortical reorganization in case the facial palsy is reversible. Further animal studies provide evidence that the recovery of facial function after facial nerve reconstructive surgery is limited not only by collateral axonal and terminal nerve sprouting ${ }^{5}$; the defective healing is also affected by central cortical changes. ${ }^{6}$ Almost nothing, however, is known about the reversibility or about later changes of cortical plasticity. In particular, the effects of regeneration of the facial nerve in humans on cortical plasticity, such as in connection with neuroreconstructive surgery, are unknown. The functional results of facial nerve reconstructive surgery are extremely variable. ${ }^{7}$ The influence of cortical reorganization processes on this variability is not yet clear.

In the present functional magnetic resonance imaging (fMRI) study, we investigated cortical reorganization after facial nerve reconstructive surgery, such as hypoglossal-facial nerve anastomosis (HFA), hypoglossalfacial nerve jump anastomosis (HFJA), and facial nerve interpositional graft (FNIG). We implemented previously 
TABLE I.

Patient Characteristics and Outcome of the Functional Facial Recovery.

\begin{tabular}{|c|c|c|c|c|c|c|c|c|c|c|}
\hline $\begin{array}{l}\text { Patient } \\
\text { No. }\end{array}$ & $\begin{array}{l}\text { Age, } \\
\text { yr }\end{array}$ & Sex & Etiology of the Facial Palsy & $\begin{array}{c}\text { Type of } \\
\text { Neuroreconstructive } \\
\text { Surgery }\end{array}$ & Op Side & $\begin{array}{l}\text { Denervation } \\
\text { Time, mo* }\end{array}$ & $\begin{array}{l}\text { Final HB } \\
\text { Grading }\end{array}$ & $\begin{array}{c}\text { Final May } \\
\text { Grading }\end{array}$ & $\begin{array}{l}\text { Voluntary } \\
\text { Activity }^{\dagger}\end{array}$ & Synkinesis ${ }^{\dagger}$ \\
\hline 1 & 26 & $\mathrm{M}$ & Parotid carcinoma & HFJA & Right & 0 & II & II & Strong & Mild \\
\hline 2 & 54 & M & Vestibular schwannoma & HFJA & Right & 6 & II & II & Strong & Moderate \\
\hline 3 & 65 & $\mathrm{~F}$ & Meningeoma & HFJA & Right & 18 & III & IV & Weak & Moderate \\
\hline 4 & 27 & $\mathrm{~F}$ & Parotid carcinoma & HFA & Left & 0 & III & II & Strong & Moderate \\
\hline 5 & 38 & $\mathrm{~F}$ & Parotid carcinoma & HFA & Left & 5 & III & III & Moderate & Mild \\
\hline 6 & 63 & M & Vestibular schwannoma & HFA & Left & 12 & IV & III & Weak & Strong \\
\hline 7 & 27 & M & Facial nerve neuroma & HFA & Right & 0 & III & IV & Moderate & Moderate \\
\hline 8 & 45 & $\mathrm{~F}$ & Facial nerve neuroma & FNIG & Left & 0 & III & III & Moderate & Strong \\
\hline 9 & 38 & M & Facial nerve neuroma & FNIG & Left & 0 & II & II & Strong & Strong \\
\hline 10 & 36 & $\mathrm{~F}$ & latrogenic lesion & FNIG & Left & 0 & III & II & Strong & Strong \\
\hline
\end{tabular}

*Interval between onset of palsy and surgical reconstruction.

${ }^{\dagger}$ Assessed with electromyography.

$\mathrm{Op}=$ operative; HB = House-Brackmann; $\mathrm{M}=$ male; $\mathrm{F}=$ female; HFJA = hypoglossal-facial nerve jump anastomosis; HFA = hypoglossal-facial nerve anastomosis; FNIG = facial nerve interpositional graft.

developed experimental designs to demonstrate the possibility of discriminating robustly the cortical representation sites of tongue and lip movements in healthy volunteers with fMRI. ${ }^{8}$ The present study should help to define cortical reorganization patterns that are supportive to induce optimal functional facial nerve regeneration. Furthermore, the results should establish fMRI as a routine diagnostic tool to monitor and check the efficacy of facial nerve training protocols.

\section{MATERIALS AND METHODS}

Ten patients who had undergone facial nerve reconstructive surgery (five females and five males; all right-handed as assessed by the Edinburgh Handedness Inventory ${ }^{9}$ ) ranging in age from 27 to 65 years took part in the study (mean \pm standard deviation: $42 \pm 14$ years). The patients' demographic and surgical characteristics are summarized in Table I. The patients demonstrated no other neurologic deficit except the state after unilateral facial palsy.

To reanimate the mimic musculature, we performed a classic HFA in four patients, an HFJA in three patients, and an FNIG in three patients. In each case, the greater auricular or sural nerve was used as donor nerve for the jump technique and the direct interposition grafts. More details on the surgical technique are given elsewhere. ${ }^{7}$ Postoperative physiotherapy but not electrostimulation was allowed. All patients returned for a follow-up examination every 3 months after surgery until functional recovery reached optimal outcome. The follow-up examination included standardized electromyography with bipolar needle electrodes with a Neuroscreen Plus system (Jaeger-Toennies, Inc., Höchberg, Germany). The recordings were analyzed for spontaneous fibrillation potentials, the degree of voluntary polyphasic reinnervation potentials, and synkinetic activity. Details on the recorded muscles and recording techniques are published elsewhere. ${ }^{10}$ The final facial function was reported by using the House-Brackmann score classifying facial function in six categories (ranging from grade I [normal function] to grade VI [complete paralysis $]^{11}$ ) plus gross asymmetry at rest. In addition, the May facial nerve grading scale was used. ${ }^{12}$ This grading scale was designed for reporting results after facial nerve reconstruction in particular. Briefly, five grades ranging from grade I (superb) to grade V (failure) are differentiated depending on tone and symmetry at rest and at motion and on the quality of the mimetic movements.

The time interval between onset of the palsy and nerve reconstruction varied from 0 to 18 months (mean, $4 \pm 6$ months). The fMRI measurements were performed 12 to 51 months (mean, $15 \pm 7$ months) after surgery; thus, axonal regeneration was complete at the time of the fMRI investigation. All participants gave their written, informed consent, and the study was approved by the local ethics committee and was performed according to the guidelines of the Declaration of Helsinki 1975.

During fMRI, the patients laid supine in the scanner and their heads were fixated by a forehead restraining strip and foam pads for minimizing unintended head movements. For facial motor stimulation, the patients were asked to execute symmetrical lip pursing (facial paradigm). The HFA and HFJA patients performed an additional run with horizontal tongue excursions (hypoglossal paradigm). During these motor tasks, the patients were asked to keep their mouths closed and to avoid tongue movements during lip pursing and vice versa. The patients were instructed to perform repetitive movements rhythmically at a self-paced velocity. The patients were trained on the tasks before being placed in the MRI scanner. Either a classic block design or an event-related design was used. The block design paradigm has been described elsewere. ${ }^{8}$ Because it had become apparent that the event-related design was more comfortable for the patients, the block design was only used in the first four patients (Table II). In pilot experiments with healthy controls, we found that there were no significantly different results between these two experimental designs; both yielded strong activations in the accordant parts of the motor cortex (Guntinas-Lichius et al., not published). In the eventrelated design, each functional run included 16 motor task repetitions of 1 second every 20 seconds. Three functional runs per condition were performed. The beginning and end of each task/ resting period were visually signaled with color-coded cues by using MRI-suitable light-emitting diodes.

MRI data were obtained with a 1.5-T scanner (Gyroscan Intera, Powertrak 6000 gradient amplifier; Philips, Best, The Netherlands) as described by Hesselmann et al. ${ }^{8}$

For statistical analysis, the acquired functional images were preprocessed and analyzed with the SPM8 software 
TABLE II.

Cortical Activation by Peripheral Facial Nerve (Lip Movements) and Hypoglossal Nerve (Tongue Movements): List of Areas With the Maximal $t$ Value in the Motor Cortex.

\begin{tabular}{|c|c|c|c|c|c|c|c|c|c|c|c|c|c|c|}
\hline \multirow{3}{*}{$\begin{array}{l}\text { Subject } \\
\text { No. }\end{array}$} & \multirow{3}{*}{$\begin{array}{l}\text { Kind of } \\
\text { Surgery }\end{array}$} & \multirow{3}{*}{$\begin{array}{c}\text { Interval } \\
\text { S-fMRI, mo }\end{array}$} & \multirow[b]{3}{*}{ Paradigm } & \multicolumn{5}{|c|}{ Ipsilateral Hemisphere } & \multicolumn{5}{|c|}{ Contralateral Hemisphere } & \multirow[b]{3}{*}{ Desigr } \\
\hline & & & & \multicolumn{3}{|c|}{$\begin{array}{c}\text { Talairach } \\
\text { Coordinates }\end{array}$} & \multirow[b]{2}{*}{$t$} & \multirow{2}{*}{$\begin{array}{l}\text { Cluster } \\
\text { Size }\end{array}$} & \multicolumn{3}{|c|}{$\begin{array}{l}\text { Talairach } \\
\text { Coordinates }\end{array}$} & \multirow[b]{2}{*}{$t$} & \multirow{2}{*}{$\begin{array}{c}\text { Cluster } \\
\text { Size }\end{array}$} & \\
\hline & & & & $x$ & $y$ & z & & & $x$ & $y$ & z & & & \\
\hline \multirow[t]{2}{*}{1} & HFJA & 21 & Facial & 60 & -8 & 46 & 25.00 & 3,014 & -46 & -12 & 34 & 18.52 & 2,063 & ER \\
\hline & & & Hypoglossal & 64 & -2 & 32 & 25.19 & 5,087 & -58 & -6 & 26 & 20.83 & 2,186 & \\
\hline \multirow[t]{2}{*}{2} & HFJA & 18 & Facial & 50 & -8 & 56 & 8.72 & 91 & -56 & -12 & 40 & 9.63 & 363 & ER \\
\hline & & & Hypoglossal & 58 & -4 & 24 & 8.29 & 124 & -60 & 0 & 24 & 9.22 & 288 & \\
\hline \multirow[t]{2}{*}{3} & HFJA & 13 & Facial & 54 & -6 & 34 & 11.23 & 906 & -50 & -8 & 40 & $3.44^{*}$ & * & $\mathrm{BD}$ \\
\hline & & & Hypoglossal & 52 & -4 & 24 & 9.16 & 668 & -56 & -6 & 26 & $4.34^{*}$ & * & \\
\hline \multirow[t]{2}{*}{4} & HFA & 51 & Facial & -60 & -6 & 40 & 23.37 & 5,542 & 60 & -6 & 32 & 21.94 & 2,770 & $B D$ \\
\hline & & & Hypoglossal & -60 & -6 & 32 & 28.57 & 5,021 & 66 & 0 & 30 & 30.75 & 6,437 & \\
\hline \multirow[t]{2}{*}{5} & HFA & 12 & Facial & -54 & -10 & 30 & 7.49 & 149 & 58 & -6 & 38 & 6.21 & 71 & ER \\
\hline & & & Hypoglossal & -52 & -6 & 42 & $4.88^{\dagger}$ & $\dagger$ & 58 & -4 & 26 & $4.88^{\dagger}$ & $\dagger$ & \\
\hline \multirow[t]{2}{*}{6} & HFA & 22 & Facial & -50 & -12 & 50 & $7.50^{\dagger}$ & $\dagger$ & 66 & -12 & 20 & $4.34^{\dagger}$ & $\dagger$ & BD \\
\hline & & & Hypoglossal & -50 & -2 & 44 & $5.06^{\dagger}$ & $\dagger$ & 46 & -8 & 56 & $3.79^{\dagger}$ & $\dagger$ & \\
\hline \multirow[t]{2}{*}{7} & HFA & 38 & Facial & 60 & -6 & 38 & 14.20 & 931 & -52 & -2 & 30 & 19.63 & 1,631 & ER \\
\hline & & & Hypoglossal & 63 & 0 & 24 & 18.41 & 6,225 & -54 & -4 & 30 & 21.34 & 3,694 & \\
\hline \multirow[t]{2}{*}{ Group $^{\ddagger}$} & $\mathrm{HF}(\mathrm{J}) \mathrm{A}$ & 25 & Facial & -44 & -12 & 40 & $6.39^{\dagger}$ & + & 58 & -10 & 34 & $4.37^{\dagger}$ & + & \\
\hline & & & Hypoglossal & -44 & -12 & 40 & $8.17^{\dagger}$ & $\dagger$ & 62 & -16 & 22 & $4.98^{\dagger}$ & $\dagger$ & \\
\hline 8 & FNIG & 13 & Facial & -54 & -14 & 36 & 14.2 & 1,472 & 52 & -10 & 36 & 13.94 & 1,198 & BD \\
\hline 9 & FNIG & 12 & Facial & -46 & -12 & 54 & 9.87 & 152 & 58 & -14 & 44 & 9.07 & 258 & ER \\
\hline 10 & FNIG & 13 & Facial & -48 & -8 & 42 & 9.84 & 746 & 66 & -14 & 40 & 9.02 & 651 & ER \\
\hline
\end{tabular}

If not otherwise indicated, all thresholds are at $P<.05$ (family-wise error corrected) at a cluster level $k=30$.

${ }^{\star} P<.01$ (uncorrected).

${ }^{\dagger} P<.001$ (uncorrected)

¥Magnetic resonance imaging data for patients with pareses on the right side were reanalyzed with flipped volumes to allow a group analysis. This results in a virtual left-sided facial nerve reconstruction.

Interval S-fMRI = interval surgery to fMRI; HFJA = hypoglossal-facial nerve jump anastomosis; ER = event-related; BD = block design; HFA = hypoglossal-facial nerve anastomosis; FNIG = facial nerve interpositional graft.

package (Wellcome Department of Cognitive Neurology, London, England, U.K.) running under a Matlab V7.83 environment (Mathworks, Inc., Sherborn, MA). Preprocessing included realignment, slice timing (only for the event-related paradigm), coregistration of the high-resolution scans with the functional images, normalization, and spatial smoothing with an 8-mm full-width half-maximum isotropic Gaussian kernel. If not otherwise indicated, the $P$ values obtained for first-level analysis were family-wise error corrected with a threshold set at $P<.05$ and an extent of 30 voxels. Furthermore, a second-level group analysis of the HFJA group was performed at a threshold of $P<.001$ (uncorrected). MRI data for patients with facial nerve surgery on the right side were flipped in the sagittal plane as described by Rijntjes et al. ${ }^{1}$ to enable the inclusion of all subjects in the group analysis.

\section{RESULTS}

\section{Clinical Outcome}

The patients were followed until full recovery. Facial function improved until approximately 1 year after surgery and remained stable for another year. Revision surgery was not necessary in any case. An overview of the functional outcome is given in Table I. All patients developed a normal resting tone; that is, the palsy was not visible during rest. All patients with HFA showed fibrillations in the tongue and mild atrophy of the lateral tongue on the side of surgery. In contrast, the patients with HFJA showed normal tongue movement without signs of tongue atrophy. Regeneration started between 3 and 6 months after surgery. Synkinetic activity started at 6 to 9 months and reached its maximum 12 months after surgery. Facial movements but also synkinesis revealed by clinical and electromyographic examination were most pronounced in patients with classic HFA. With the House-Brackmann scale, the final functional result varied from grade II to IV (mean: grade III). Applying May's grading resulted in outcomes varying from II to IV (mean: III).

\section{MRI Results}

The structural MRI scan showed an intact brain in each patient. After HFA or HFJA, when performing lip pursing, five of the seven patients showed the strongest activations on the ipsilateral side related to facial nerve reconstructive surgery (Tables II and III). Three patients (HFJA: patients 1 and 2; HFA: patient 6) showed the strongest activation in the facial area of the motor cortex 
TABLE III.

Overview of Cortical Activation Within Facial and Hypoglossal Motor Cortex Representation Areas During Lip Movement (Facial Paradigm) and Tongue Movement (Hypoglossal Paradigm).

\begin{tabular}{|c|c|c|c|c|c|c|}
\hline \multirow[b]{2}{*}{ Subject No. } & \multirow[b]{2}{*}{ Kind of Surgery } & \multirow[b]{2}{*}{$\begin{array}{l}\text { Ipsilateral or } \\
\text { Contralateral to } \\
\text { Lesion Site }\end{array}$} & \multicolumn{2}{|c|}{ Facial Paradigm } & \multicolumn{2}{|c|}{ Hypoglossal Paradigm } \\
\hline & & & $\begin{array}{l}\text { Activation in } \\
\text { Facial Presentation } \\
\text { Motor Cortex }\end{array}$ & $\begin{array}{l}\text { Activation in } \\
\text { Hypoglossal Presentation } \\
\text { Motor Cortex }\end{array}$ & $\begin{array}{l}\text { Activation in } \\
\text { Facial Presentation } \\
\text { Motor Cortex }\end{array}$ & $\begin{array}{l}\text { Activation in } \\
\text { Hypoglossal } \\
\text { Presentation } \\
\text { Motor Cortex }\end{array}$ \\
\hline \multirow[t]{2}{*}{1} & HFJA & Ipsilateral & + & $(+)$ & $(+)$ & ++ \\
\hline & & Contralateral & + & + & - & ++ \\
\hline \multirow[t]{2}{*}{2} & HFJA & Ipsilateral & $(+)$ & $(-)$ & - & + \\
\hline & & Contralateral & $(+)$ & $(-)$ & - & + \\
\hline \multirow[t]{2}{*}{3} & HFJA & Ipsilateral & - & ++ & - & ++ \\
\hline & & Contralateral & - & - & - & - \\
\hline \multirow[t]{2}{*}{4} & HFA & Ipsilateral & - & ++ & - & ++ \\
\hline & & Contralateral & - & ++ & - & ++ \\
\hline \multirow[t]{2}{*}{5} & HFA & Ipsilateral & $(+)^{*}$ & ++ & $(+)^{*}$ & $+^{*}$ \\
\hline & & Contralateral & - & ++ & - & $+^{*}$ \\
\hline \multirow[t]{2}{*}{6} & HFA & Ipsilateral & + & - & + & $++^{*}$ \\
\hline & & Contralateral & - & - & $(+)^{*}$ & - \\
\hline \multirow[t]{2}{*}{7} & HFA & Ipsilateral & + & ++ & $(-)$ & ++ \\
\hline & & Contralateral & ++ & ++ & + & ++ \\
\hline \multirow[t]{2}{*}{ Group HF(J)A } & & Ipsilateral & $+^{*}$ & $+^{*}$ & $+^{*}$ & $+^{*}$ \\
\hline & & Contralateral & - & $+^{*}$ & - & $+^{*}$ \\
\hline \multirow[t]{2}{*}{8} & FNIG & Ipsilateral & ++ & $(-)$ & NA & NA \\
\hline & & Contralateral & ++ & $(+)$ & NA & NA \\
\hline \multirow[t]{2}{*}{9} & FNIG & Ipsilateral & + & $(+)$ & NA & NA \\
\hline & & Contralateral & + & - & NA & NA \\
\hline \multirow[t]{2}{*}{10} & FNIG & Ipsilateral & ++ & - & NA & NA \\
\hline & & Contralateral & $(+)$ & $(+)$ & NA & NA \\
\hline
\end{tabular}

If not otherwise indicated, all thresholds are at $P<.05$ (family-wise error corrected) at a cluster level $k=30$.

${ }^{*} P<.01$ (uncorrected).

HFJA = hypoglossal-facial nerve jump anastomosis; HFA = hypoglossal-facial nerve anastomosis; FNIG = facial nerve interpositional graft; ++ = strong activation; $+=$ moderate activation; $(+)=$ weak activation; $-=$ no activation; $(-)=$ very weak activation; NA $=$ not applied.

as described by Hesselmann et al. ${ }^{8}$ The remaining four patients (three patients with HFA, one patient with HFJA) showed their main activation in the hypoglossal area according to Hesselmann et al. (HFJA: patient 3; HFA: patients 4, 5, and 7). Patients 1 and 7 simultaneously activated facial and hypoglossal areas bilaterally (see Fig. 1 for patient 1). Further activated areas were found in the supplementary motor area (seven of seven HFA/HFJA patients), gyrus postcentralis/gyrus supramarginalis (seven of seven), basal ganglia (five of seven), thalamus (two of seven), cerebellum (three of seven), insula (six of seven), rolandic operculum (six of seven), and amygdala (three of seven). An overview of the cortical activation outside the primary sensorimotor areas for each subject is given in Table IV.

During the tongue movement task, all HFA and HFJA patients activated the hypoglossal area. Only patients 3 and 6 showed almost exclusively ipsilateral motor cortex activation during the facial and hypoglossal stimulation task (Table III). Generally, hypoglossal activations resulted in a larger voxel size and higher $t$ values compared with facial activations (Table II). Patients 1, 6, and 7 also activated the ipsilateral facial area during tongue movements. Further activated areas in the tongue task were the supplementary motor area (seven of seven), basal ganglia (five of seven), thalamus (three of seven), cerebellum (four of seven), insula (six of seven), gyrus postcentralis/gyrus supramarginalis (seven of seven), rolandic operculum (six of seven), and amygdala (seven of seven).

In the group analysis, including all HFA and HFJA patients, a stronger ipsilateral activation in the facial stimulation task $\left(t_{\max } 6.39\right.$ vs. 4.37 ) as well as in the hypoglossal stimulation task ( $t_{\max } 8.17$ vs. 4.98 ) could be seen. Interestingly, in both tasks, the same areas were activated-in the ipsilateral hemisphere the facial and tongue area of the motor cortex and in the contralateral hemisphere only the tongue area (Fig. 2). Higher $t$ values in the tongue movement task compared to the lip pursing task (as already observed in the single-subject analyses) were observed.

In the lip pursing task, all FNIG patients showed the strongest activations on the ipsilateral side of the facial nerve surgery (Tables II and III). All FNIG patients activated the known facial area bilaterally (Fig. 3). Fewer additional areas outside the primary motor cortex 

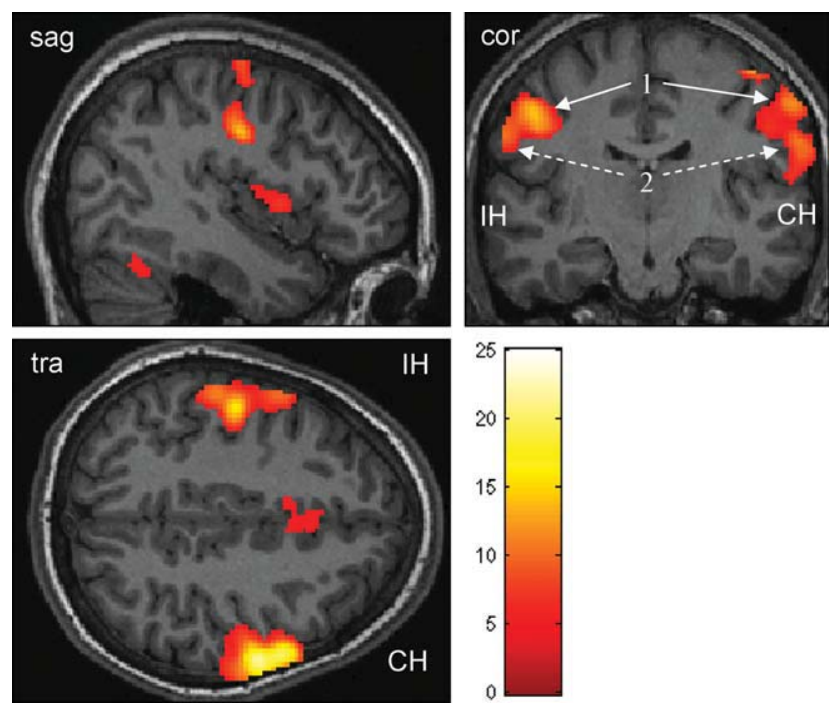

Fig. 1. Example of functional magnetic resonance imaging activations in a patient who underwent hypoglossal-facial nerve jump anastomosis surgery with the lip pursing task (patient 1). Bilateral activations in the facial and hypoglossal area can be observed. $P$ $=.05$ (family-wise error corrected). $\mathrm{IH}=$ ipsilateral hemisphere; $\mathrm{CH}$ = contralateral hemisphere; 1 = facial area of motor cortex; $2=$ tongue area of motor cortex; sag = sagittal; cor = coronal; tra = transversal magnetic resonance imaging slice.

were found in this group compared with the HFA group and the HFJA group (Table IV); three of three patients showed activations in the supplementary motor area, two of three were in the gyrus postcentralis/gyrus supra- marginalis and in the Rolandic operculum, and one of three was in thalamus and insula.

\section{DISCUSSION}

Movement of the tongue by hypoglossal nerve activation and movement of the lips by facial nerve activation lead to selective motor cortex activation, as has been demonstrated by previous fMRI investigations, ${ }^{8}$ and for tongue and upper and lower face movements by TMS. ${ }^{13,14}$ Transient (due to Bell's palsy) or permanent (due to vestibular schwannoma, for example) peripheral facial nerve lesions lead to fast (within 1 month) and long-lasting (more than 30 years) reorganization of the human cortex. Investigations with TMS and PET have shown that hand movements lead to enlargement of the hand field in the somatosensory cortex contralateral to the facial palsy side, mainly by lateral extension into the presumed face area. ${ }^{1}$ Moreover, TMS revealed that there seems to be a mild enlargement of the facial motor cortex for the output to the intact facial side ${ }^{15}$ and an invasion of the facial motor cortex by the tongue motor representation. ${ }^{2}$ Such spatial reorganization of cortical motor output maps owing to expansions of cortical representations of unaffected muscles into adjacent cortex areas are well described for limb amputee patients. ${ }^{16}$ For a bilateral hand amputee, it has been shown that amputationinduced cortical reorganization was reversed following bilateral hand transplantation 4 years after amputation. ${ }^{17}$ In correspondence, we show that patients with

\section{TABLE IV.}

Overview of Cortical Activation Outside Primary Motor Cortex During Lip Movement (Facial Paradigm) and Tongue Movement (Hypoglossal Paradigm).

\begin{tabular}{llccccccccc}
\hline Subject & Kind of & Supplementary & Gyrus Postcentralis/Gyrus & Basal & Rolandic & & & & \\
No. & Surgery & Motor Area & Supramarginalis & Ganglia & Thalamus & Cerebellum & Insula & Operculum & Amygdala \\
\hline
\end{tabular}

\section{Facial paradigm}

$1 \quad$ HFJA

2 HFJA

$3 \quad$ HFJA

$4 \quad$ HFA

$5 \quad$ HFA

$6 \quad$ HFA

7 HFA

$8 \quad$ FNIG

$9 \quad$ FNIG

$10 \quad$ FNIG

Hypoglossal paradigm

$\begin{array}{llll}1 & \text { HFJA } & + & \\ 2 & \text { HFJA } & + & + \\ 3 & \text { HFJA } & + & + \\ 4 & \text { HFA } & + & + \\ 5 & \text { HFA } & + & + \\ 6 & \text { HFA } & + & + \\ 7 & \text { HFA } & + & -\end{array}$

HFJA = hypoglossal-facial nerve jump anastomosis; HFA = hypoglossal-facial nerve anastomosis; FNIG $=$ facial nerve interpositional graft; $+=$ activated; $-=$ not activated. 

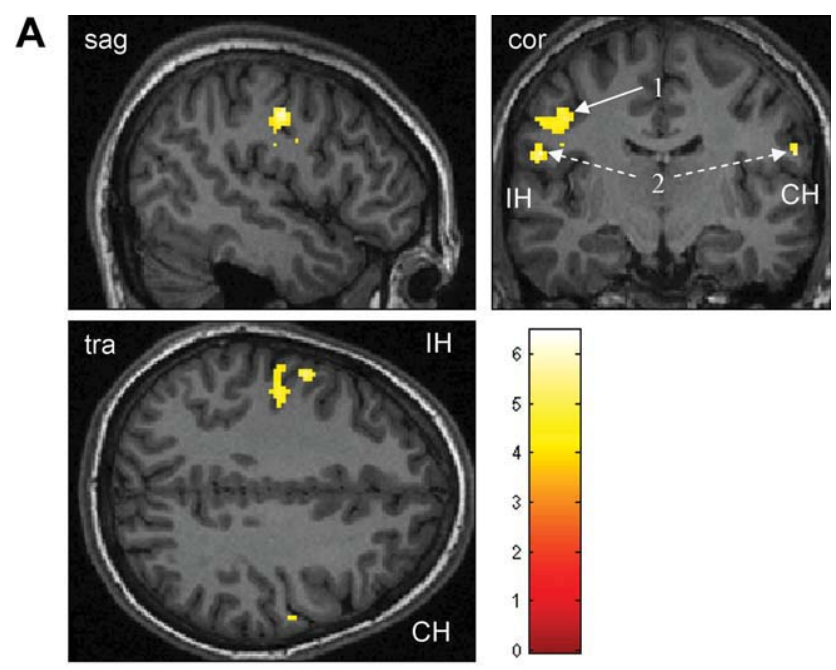

B
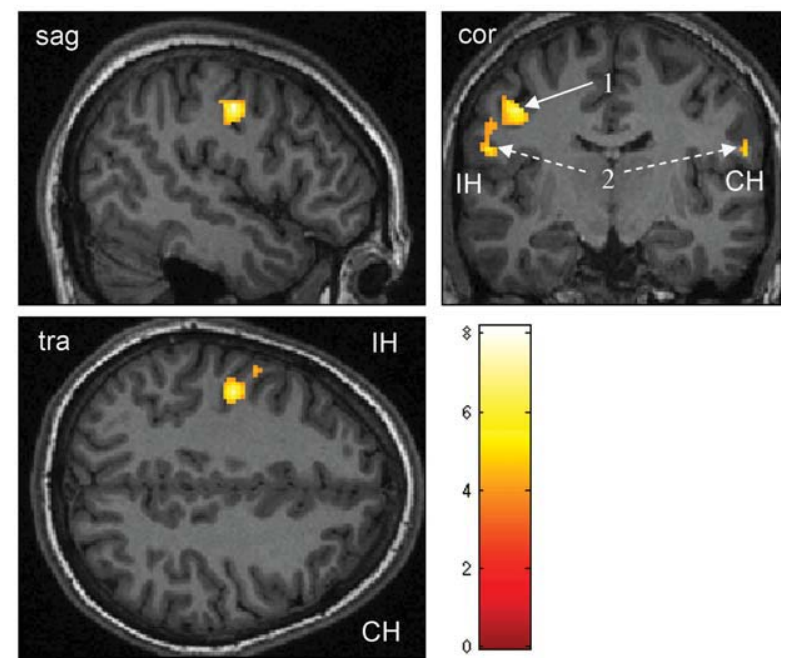

Fig. 2. Group analysis of all patients who underwent hypoglossalfacial nerve jump anastomosis surgery during (A) facial nerve stimulation using the lip pursing task and (B) hypoglossal stimulation using the tongue movement task. $P<.001$ (uncorrected). $\mathrm{IH}=\mathrm{ip}-$ silateral hemisphere; $\mathrm{CH}=$ contralateral hemisphere; $1=$ facial area of motor cortex; 2 = tongue area of motor cortex; sag = sagittal; cor $=$ coronal; tra $=$ transversal magnetic resonance imaging slice.

FNIG and completed regeneration use the original cortical facial representation area as in healthy adults. We suppose that motor cortical reorganization is also restored after peripheral direct nerve grafting.

HFA and HFJA are fascinating surgical procedures because the underlying cross-nerve paradigm results in facial movements by thinking of or trying to perform tongue movements (in HFA) or by performing tongue movements (in HFJA). Such a complete or partial exchange of a motor function of a cranial nerve (i.e., tongue movements) to a completely different motor function of another cranial nerve (mimic movements) is unique in peripheral nerve surgery and leads to sufficient facial function in most patients. ${ }^{7}$ The present study gives first data on cortical reorganization for such an exceptional neurobiological situation. During the lip pursing task, only two subjects (patient 2 with HFJA and patient 6 with HFA) showed predominant activation in the presumed facial area. Interestingly, patient 6 was the patient with the worst outcome of all patients. Otherwise, HFA patients showed predominant activation in the original hypoglossal motor cortex, and HFJA patients showed a mixed activation of both motor areas (Fig. 4). It seems that cortical activation for facial movements after the complete peripheral rewiring by HFA is bypassed to the hypoglossal motor cortex. In HFJA, the split peripheral nerve function seems to need parallel activation in hypoglossal and facial areas to induce satisfactory facial movement. In contrast, during tongue movements, HFJA patients showed predominant activation in presumed hypoglossal motor cortex similar to healthy controls, but HFA patients no longer able to control the hemitongue with the hypoglossal nerve activate dominantly the hypoglossal area but also the facial area. The design of the present study does not allow for differentiation between whether the cortical activation in the presumed hypoglossal area is part of the planning or the completion of the lip movements.

In general, the present study is limited by the small study sample, allowing a group analysis only by combining the groups of HFA and HFJA patients. Viewed realistically, a clinical study with a larger sample size for such relatively infrequent surgery using this elaborate methodology is not feasible.

Furthermore, the variability of the patients' characteristics (duration of denervation before nerve surgery, interval surgery to fMRI, etiology) seemed to influence the variability of the imaging data. These limitations did not allow for the performance of a correlation analysis of cortical activation patterns to clinical outcome. Furthermore, the heterogeneity of the sample did not allow for a detailed comparison of the activation on the
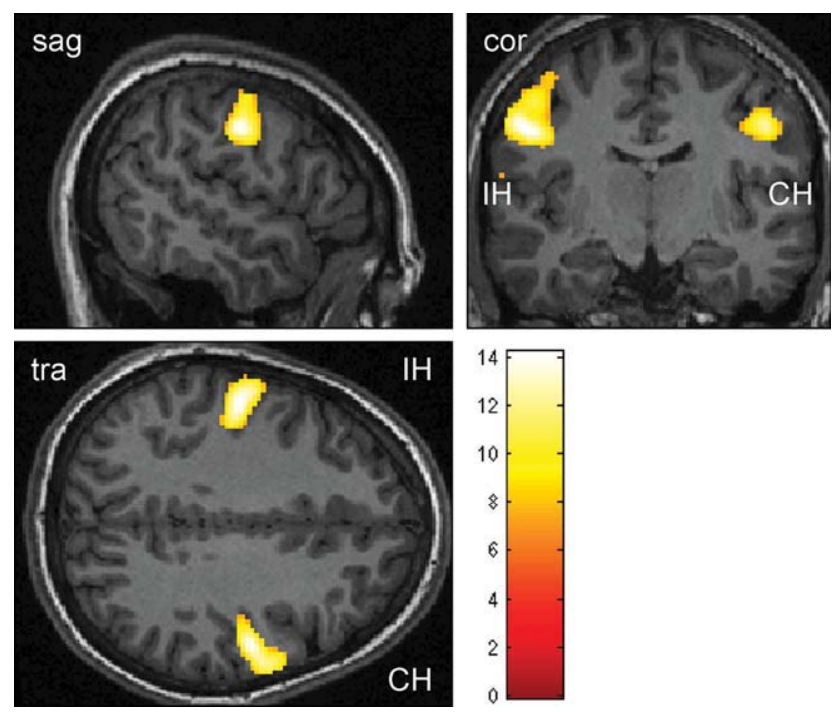

Fig. 3. Example of cerebral activations in a patient who underwent facial nerve interpositional graft surgery (patient 8) using the lip pursing task. Bilateral activations in the facial motor cortex area were observed. $P<05$ (family-wise error corrected). $\mathrm{IH}=$ ipsilateral hemisphere; $\mathrm{CH}=$ contralateral hemisphere; sag = sagittal; cor = coronal; tra $=$ transversal magnetic resonance imaging slice. 
Fig. 4. Schematic description of the presumed hypoglossal (M XII) and facial (M VII) functional magnetic resonance imaging activation during lip or tongue movements for the healthy state/ after facial nerve interpositional graft (FNIG), hypoglossal-facial nerve anastomosis (HFA), or hypoglossal-facial nerve jump anastomosis (HFJA). Tongue movement task was not performed in patients with FNIG. Open arrows = corticofugal fibers; closed arrows $=$ peripheral nerve; graft side is indicated in orange color. [Color figure can be viewed in the online issue, which is available at

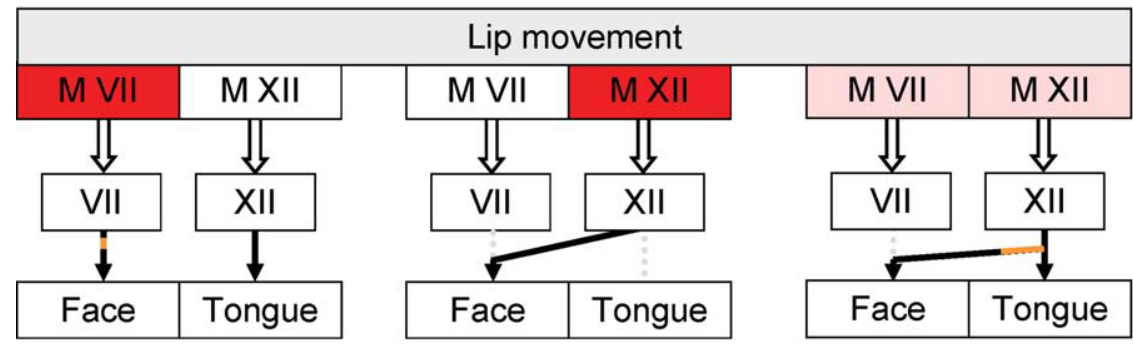
wileyonlinelibrary.com.]

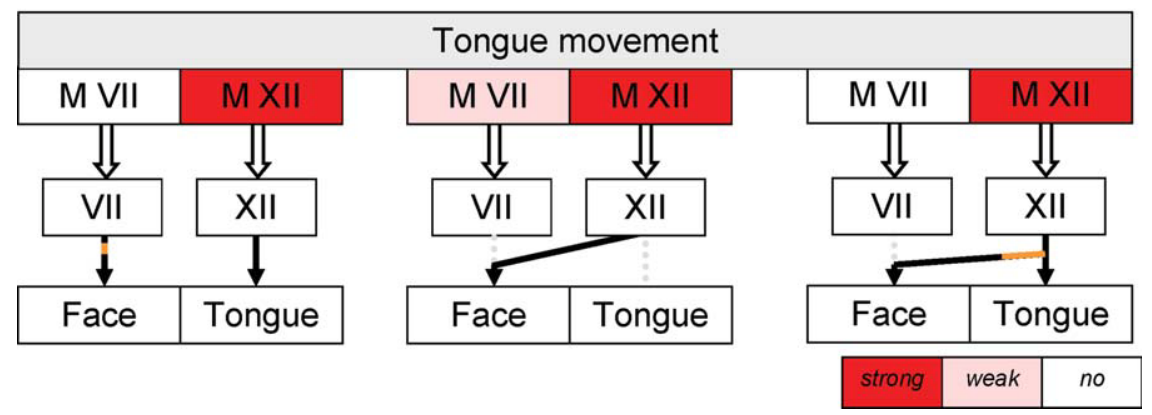

contralateral side versus that on the ipsilateral hemisphere. In regard to the activation in secondary and tertiary cortical areas, it can be assumed that facial activation with nerve reconstructions seems not to be different from normal facial activation. ${ }^{18}$ Differences between the types of nerve reconstruction were not obvious. The supplementary motor areas are important to plan and modulate complex movement impulses that are transferred from the primary motor cortex to the motor nuclei within the brainstem. We conclude that the primary motor cortex area and not the supplementary area is the main component of the cortical reorganization after peripheral nerve rewiring.

What are the mechanisms behind the cortical reorganization? Animal models of cortical map plasticity have shown that the first step in cortical map reorganization is the loss of local interneuron inhibition and the unmasking of pre-existing horizontal cortical connections under active up and down regulation of local $\alpha$-aminobutyric acid- and glutamate-related synaptic function. ${ }^{19,20}$ These synaptic changes take place simultaneously to massive local glia cell activation and neural immediate early gene activation known to be related to synaptic remodelling. 6,21 After this fast initial reorganization, the candidate mechanisms for modulation of changes over the long term are strengthening of pre-existing synaptic connections by long-term potentiation and weakening by long-term depression. $^{22}$ In the future, the plasticity of the system will offer the possibility of interfering by using repetitive TMS when we better know which kind of reorganization pattern fits to better functional mimic outcome.

Of course, to completely understand facial motor control and reorganization after neuroreconstructive surgery, the following items will need to be addressed:

1) It is necessary to analyze the afferent part (i.e., the trigeminal nerve), as afferent feedback is an important part of motor control and seems to be especially important to support optimal functional nerve repair. ${ }^{23}$
2) Facial palsy before and after nerve reconstruction will lead to changes in the intracortical inhibition and facilitation of motor cortex activity during facial movements. ${ }^{24}$

3) Animal studies have shown the existence of a trigemino-reticulo-facial and a trigemino-reticulo-hypoglossal network in the brainstem important for orofacial motor control. ${ }^{25}$ The brainstem has not yet been analyzed in patients with facial nerve repair.

In the future, we will evaluate more patients in a longitudinal study to better understand the time course of reorganization during facial regeneration. Furthermore, we would like to combine functional brain imaging with mimic training to elucidate training effects on cortical reorganization.

\section{CONCLUSION}

Investigations by fMRI have shown different cortical reorganization after FNIG in comparison with crossnerve surgery via classic HFA or HFJA. After interpositional grafting, the original motor cortex activation seems to be restored, whereas after HFA, activation of facial movements seems to be shifted predominantly to the presumed hypoglossal motor cortex. After HFJA, activation appears to be shared by facial and hypoglossal cortical area.

\section{BIBLIOGRAPHY}

1. Rijntjes M, Tegenthoff M, Liepert $J$, et al. Cortical reorganization in patients with facial palsy. Ann Neurol 1997;41:621-630.

2. Rodel RM, Tergau F, Markus H, Laskawi R. Bilateral changes in cortical motor representation of the tongue after unilateral peripheral facial paralysis: evidence from transcranial magnetic stimulation. Ann Otol Rhinol Laryngol 2004;113:951-955.

3. Sanes JN, Suner S, Donoghue JP. Dynamic organization of primary motor cortex output to target muscles in adult rats. I. Long-term patterns of reorganization following motor or mixed peripheral nerve lesions. Exp Brain Res 1990;79:479-491. 
4. Donoghue JP, Suner S, Sanes JN. Dynamic organization of primary motor cortex output to target muscles in adult rats. II. Rapid reorganization following motor nerve lesions. Exp Brain Res 1990;79:492-503.

5. Guntinas-Lichius O, Irintchev A, Streppel M, et al. Factors limiting motor recovery after facial nerve transection in the rat: combined structural and functional analyses. Eur J Neurosci 2005;21:391-402.

6. Peeva GP, Angelova SK, Guntinas-Lichius O, et al. Improved outcome of facial nerve repair in rats is associated with enhanced regenerative response of motoneurons and augmented neocortical plasticity. Eur $J$ Neurosci 2006;24:2152-2162.

7. Guntinas-Lichius O, Streppel M, Stennert E. Postoperative functional evaluation of different reanimation techniques for facial nerve repair Am J Surg 2006;191:61-67.

8. Hesselmann V, Sorger B, Lasek K, et al. Discriminating the cortical representation sites of tongue and up movement by functional MRI. Brain Topogr 2004;16:159-167.

9. Oldfield RC. The assessment and analysis of handedness: the Edinburgh inventory. Neuropsychologia 1971;9:97-113.

10. Grosheva M, Wittekindt C, Guntinas-Lichius O. Prognostic value of electroneurography and electromyography in facial palsy. Laryngoscope 2008;118:394-397.

11. House JW, Brackmann DE. Facial nerve grading system. Otolaryngol Head Neck Surg 1985;93:146-147.

12. Bascom DA, Schaitkin BM, May M, Klein S. Facial nerve repair: a retrospective review. Facial Plast Surg 2000;16:309-313.

13. Roedel RM, Laskawi R, Markus H. Cortical representation of the orbicularis oculi muscle as assessed by transcranial magnetic stimulation (TMS). Laryngoscope 2001;111:2005-2011.

14. Roedel RM, Laskawi R, Markus H. Tongue representation in the lateral cortical motor region of the human brain as assessed by transcranial magnetic stimulation. Ann Otol Rhinol Laryngol 2003;112:71-76.
15. Yildiz S, Bademkiran F, Yildiz N, et al. Facial motor cortex plasticity in patients with unilateral peripheral facial paralysis. Neuro Rehabil 2007; 22:133-140.

16. Irlbacher K, Meyer BU, Voss M, Brandt SA, Roricht S. Spatial reorganization of cortical motor output maps of stump muscles in human upperlimb amputees. Neurosci Lett 2002;321:129-132.

17. Giraux P, Sirigu A, Schneider F, Dubernard JM. Cortical reorganization in motor cortex after graft of both hands. Nature Neurosci 2001;4:691-692.

18. Morecraft RJ, Stilwell-Morecraft KS, Rossing WR. The motor cortex and facial expression: new insights from neuroscience. Neurologist 2004;10: $235-249$.

19. Jacobs KM, Donoghue JP. Reshaping the cortical motor map by unmasking latent intracortical connections. Science 1991;251:944-947.

20. Franchi G, Veronesi C. Short-term reorganization of input-deprived motor vibrissae representation following motor disconnection in adult rats. $J$ Physiol 2006;574:457-476.

21. Toldi J, Laskawi R, Landgrebe M, Wolff JR. Biphasic reorganization of somatotopy in the primary motor cortex follows facial nerve lesions in adult rats. Neurosci Lett 1996;203:179-182.

22. Ziemann U, Corwell B, Cohen LG. Modulation of plasticity in human motor cortex after forearm ischemic nerve block. J Neurosci 1998;18: $1115-1123$.

23. Angelov DN Ceynowa M Guntinas-Lichius $\mathrm{O}$, et al. Mechanical stimulation of paralyzed vibrissal muscles following facial nerve injury in adult rat promotes full recovery of whisking. Neurobiol Dis 2007;26: 229-242.

24. Paradiso GO, Cunic DI, Gunraj CA, Chen R. Representation of facial muscles in human motor cortex. $J$ Physiol 2005;567:323-336.

25. Popratiloff AS, Streppel M, Gruart A, et al. Hypoglossal and reticular interneurons involved in oro-facial coordination in the rat. J Comp Neurol 2001;433:364-379. 